\title{
A UTILIZAÇÃO DO JOGO CONTIG 60 COMO RECURSO DIDÁTICO EM AULAS DE MATEMÁTICA: UMA EXPERIÊNCIA COM ALUNOS DO $7^{\circ}$ ANO $^{1}$
}

\author{
Lúcia Helena Costa Braz \\ Lucimar Alves de Almeida \\ Caroline Ester Felicíssimo Pinto
}

\begin{abstract}
RESUMO
O presente trabalho tem como objetivo apresentar um relato de experiência sobre o uso de jogos nas aulas de Matemática, mais especificamente, sobre o uso do Jogo Contig 60 em uma turma do $7^{\circ}$ ano do Ensino Fundamental de uma escola pública da cidade de Formiga/MG. A experiência foi resultado de uma proposta de atividade feita na disciplina Laboratório para o Ensino de Matemática do curso de Licenciatura em Matemática do Instituto Federal de Minas Gerais - IFMG, Campus Formiga, no semestre 2019/1. Trata-se da aplicação de um jogo em uma turma da Educação Básica, a fim de oportunizar aos licenciandos uma experiência docente e uma reflexão sobre a prática, tendo por base as discussões realizadas na disciplina acerca do uso de jogos no ensino de Matemática. O jogo em si tinha por objetivo trabalhar as quatro operações básicas, a formulação e resolução de expressões numéricas e o desenvolvimento dos raciocínios lógico e indutivo. Os resultados mostraram que o uso desse jogo em sala de aula possibilitou um trabalho lúdico da Matemática, a participação ativa dos estudantes durante o desenvolvimento da atividade, a socialização entre os colegas, a percepção de uma mudança na postura do docente que, de detentor do conhecimento, passou a mediador da aprendizagem dos alunos (experiência vivenciada pelas pesquisadoras envolvidas na atividade) e o despertar da motivação nos alunos, essencial para a aprendizagem.
\end{abstract}

Palavras-chave: Ensino de matemática. Jogos no ensino de matemática. Contig 60.

\section{THE USE OF THE CONTIG 60 GAME AS A TEACHING RESOURCE IN MATHEMATICS CLASSES: AN EXPERIENCE WITH 7TH YEAR STUDENTS}

\begin{abstract}
The present work aims to present an experience report on the use of games in Mathematics classes, more specifically, on the use of the Contig 60 Game in a class of the 7th grade of Elementary School in a public school in the city of Formiga (MG) ). The experience was the result of an activity proposal made in the discipline Laboratory for Teaching Mathematics in the Mathematics Degree course at the Federal Institute of Minas Gerais - IFMG, Campus Formiga, in the semester 2019/1. It is the application of a game in a Basic Education class, in order to provide the undergraduates with a teaching experience and a reflection on the practice,
\end{abstract}

\section{${ }^{1}$ Como citar este artigo:}

BRAZ, L. H. C.; ALMEIDA, L. A.; PINTO, C. E. F. A utilização do jogo Contig 60 como recurso didático em aulas de matemática: uma experiência com alunos do $7^{\circ}$ ano. ForScience, Formiga, v. 8, n. 2, e00765, jul./dez. 2020. DOI: 10.29069/forscience.2020v8n2.e765.

${ }^{2}$ Autor para correspondência: Lúcia Helena Costa Braz, e-mail: lucia.helena@ifmg.edu.br. 
based on the discussions held in the discipline about the use of games in the teaching of Mathematics . The game itself aimed to work on the four basic operations, the formulation and resolution of numerical expressions and the development of logical and inductive reasoning. The results showed that the use of this game in the classroom enabled a playful work in Mathematics, the active participation of students during the development of the activity, socialization among colleagues, the perception of a change in the attitude of the teacher who, knowledge, became a mediator of student learning (experience lived by the researchers involved in the activity) and the awakening of motivation in students, essential for learning.

Keywords: Mathematics teaching. Games in the teaching of mathematics. Contig 60.

\section{INTRODUÇÃO}

A literatura estudada (GRANDO, 2000; BORIN, 2007; STRAPASON; BISOGNIN, 2013; SANTOS; RODRIGUES, 2018), na disciplina Laboratório para o Ensino de Matemática, cursada pelas segunda e terceira autoras deste trabalho no semestre 2019/1 no Instituto Federal de Educação de Minas Gerais (IFMG) Campus Formiga, trouxe reflexões importantes sobre o uso de jogos no processo de ensino e aprendizagem da Matemática. Segundo Grando (2000), a utilização de jogos no ensino pode proporcionar maior interesse dos alunos, uma vez que o jogo se apresenta como uma atividade lúdica que envolve desafios, ação e competição. De acordo com a autora, os alunos tendem a se sentirem estimulados, e a reação mais comum é de alegria e de prazer pela atividade proposta.

O jogo também pode gerar mudanças no processo de ensino e aprendizagem, como, por exemplo, alterar o modelo tradicional de ensino, no qual muitas vezes o professor se baseia apenas no livro didático e em exercícios padronizados como principais recursos didáticos (STRAPASON; BISOGNIN, 2013) e, ainda, gerar situações problema que podem levar os alunos a se manterem constantemente ativos, buscando novas estratégias de jogadas e possibilidades de soluções.

Acreditamos que ensinar Matemática envolve buscar formas de desenvolver o raciocínio do aluno, fazer com que ele crie um pensamento independente e seja capaz de resolver problemas em diferentes contextos. Nesse sentido, o jogo surge como uma possibilidade, pois, em seu aspecto pedagógico, apresenta-se:

[...] produtivo ao professor que busca nele um aspecto instrumentador [...] e também produtivo ao aluno, que desenvolveria sua capacidade de pensar, refletir, analisar, compreender conceitos matemáticos, levantar hipóteses, testá-las e avaliá-las (investigação matemática), com autonomia e cooperação (GRANDO, 2000, p. 28). 
Com base na literatura estudada na disciplina Laboratório para o Ensino de Matemática e, também tendo em vista a proposta de atividade de aplicação de um jogo em uma turma da Educação Básica - optamos por aplicar o jogo Contig 60 a alunos de uma turma do $7^{\circ}$ ano de uma escola pública da cidade de Formiga/MG.

Segundo Grando (2000, p. 77), o Contig 60:

Trata-se de um jogo onde o cálculo mental com as quatro operações básicas (adição, subtração, multiplicação e divisão), a partir de números naturais, está presente na própria estrutura do jogo, ou seja, para jogar é necessário operar aritmeticamente. Além disso, é fundamental a percepção da ação das operações sobre os números, isto é, perceber, por exemplo, que o que faz um número natural aumentar muito rapidamente é uma multiplicação, já a adição faz esse aumento ser mais reduzido.

A autora destaca que é comum, no trabalho com algoritmos nas escolas, que aos alunos, sejam apresentados os valores a serem operados, ou seja, a operação é definida e, aos discentes, resta a simples tarefa de calcular o resultado e, cita, como exemplo, o exercício “[...] calcule o resultado de $17 \times 3$ ".

Segundo a autora, o cálculo é visto como uma forma de se chegar à resposta correta e, "[...] se a resposta faz sentido ou não é outro problema. A resposta, na maioria das situaçõesproblema escolares, não é muito questionada ou analisada no contexto" (GRANDO, 2000, p. 77).

Já no jogo Contig 60, a situação é inversa. "Os resultados possíveis estão evidenciados, os números a serem operados são sorteados, resta ao sujeito pensar em quais operações ele poderia chegar a obter algum dos resultados possíveis ou desejados" (GRANDO, 2000, p. 77).

Diante do exposto, este trabalho tem como objetivo principal apresentar os resultados obtidos com a aplicação do jogo Contig 60 em uma turma do $7^{\circ}$ ano do Ensino Fundamental de uma escola pública da cidade de Formiga/MG e refletir acerca do uso de jogos em sala de aula. O jogo em si tem por objetivo trabalhar quatro operações básicas, a formulação e resolução de expressões numéricas e o desenvolvimento dos raciocínios lógico e indutivo. Importante destacar que a proposta também objetivava oportunizar a experiência docente e a reflexão sobre a prática, enquanto ainda licenciandos, destacando o uso de jogos no ensino, tema discutido na disciplina Laboratório para o Ensino de Matemática.

\section{O JOGO COMO RECURSO DIDÁTICO NAS AULAS DE MATEMÁTICA}


Existem vários tipos de materiais didáticos que podem ser utilizados em sala de aula. Lorenzato (2009, p. 22-23) destaca, em especial, o material didático concreto, ressaltando: "um deles refere-se ao palpável, manipulável e o outro os não manipuláveis”. Assim, os materiais manipuláveis podem ser compreendidos como:

\begin{abstract}
Os que não possibilitam modificações em suas formas: é o caso dos sólidos geométricos construídos em madeira ou cartolina, por exemplo, que, por serem estáticos, permitem só a observação. Outros que permitem uma maior participação do aluno: é o caso do ábaco, do material montessoriano (cuisenaire ou dourado), dos jogos de tabuleiro. Mas existem aqueles materiais manipuláveis dinâmicos, que, permitem transformações por continuidade, facilitam ao aluno a realização de redescobertas, a percepção de propriedades e a construção de uma efetiva aprendizagem, que é o caso das folhas de papel ofício, palitos, cotonetes, dentre outros (LORENZATO, 2009, p. 18-19).
\end{abstract}

Um exemplo de material manipulável sugerido pela literatura (GRANDO, 2000; NACARATO, 2005; BORIN, 2007; SANTOS; RODRIGUES, 2018) são os jogos. Para Borin (2007, p. 8) " [...] a atividade de jogar, se bem orientada, tem papel importante no desenvolvimento de habilidades de raciocínio como organização, atenção e concentração, tão necessárias para o aprendizado, em especial da matemática, e para a resolução de problemas em geral".

Grando (2000, p. 28), ao discutir sobre a utilização de jogos nas aulas de Matemática como um suporte metodológico, afirma que eles têm "[...] utilidade em todos os níveis de ensino", e acredita que "O importante é que os objetivos com o jogo estejam claros, a metodologia a ser utilizada seja adequada ao nível que se está trabalhando e, principalmente, que represente uma atividade desafiadora ao aluno para o desencadeamento do processo".

A autora também destaca que a socialização em atividades com jogos é evidente, pois todo jogo possui regras, algumas estabelecidas anteriormente outras criadas pelo grupo a fim de estabelecer uma lógica de ação, e esse cumprimento ou criação das regras envolve relacionar-se com o outro que cria, pensa e age com estratégias diferentes, assim sendo, o aluno abandona o seu egocentrismo e seu interesse passa a ser social.

Outro benefício que o uso de jogos no ensino pode proporcionar é a diminuição de bloqueios existentes com conteúdo matemáticos, pois eles acabam sendo uma forma alternativa e motivadora para o ensino, e os alunos então podem apresentar melhor desempenho em seus processos de aprendizagem (BORIN, 2007; STRAPASON; BISOGNIN, 2013). 
Nesse sentido, Santos e Rodrigues (2018, p. 379) apontam que os jogos, em atividades matemáticas, tendem a atuar diretamente na "quebra do tabu do aprender matemática, mostrando aos alunos que são capazes de aprender a disciplina”.

No contexto de jogos no ensino, a literatura aponta que o professor possui um papel importante. Cabe a ele orientar os alunos através de questionamentos, fazendo com que eles assumam uma postura crítica frente aos problemas que surgirem no decorrer das jogadas. Segundo Borin (2007, p. 10):

[...] o professor será um espectador do processo de construção do saber pelo aluno, e só irá interferir ao final do mesmo, quando isso se fizer necessário, por meio de questionamentos, por exemplo, que levem os alunos a mudanças de hipóteses, apresentando situações que forcem a reflexão ou para a socialização das descobertas dos grupos, mas nunca para dar a resposta certa.

A literatura também retrata desvantagens acerca do uso de jogos; dentre essas, Lorenzato (2009) destaca o tempo gasto, que pode ser um pouco maior em relação a uma aula dita tradicional e, às vezes, pode atrapalhar outros conteúdos que devem ser trabalhados ao longo da ementa da disciplina. Mas nesse sentido, o autor destaca que é preciso levar em conta a qualidade da aprendizagem. Ele acredita que o uso de materiais didáticos no ensino pode despertar indagações não previstas pelo professor e, desta forma, se os alunos forem atendidos, o ensino poderá demandar mais tempo que o previsto, mas afirma que, em contrapartida, muitas vezes, o uso de materiais didáticos pode facilitar a aprendizagem e, então, fazer o professor ganhar tempo.

Outra questão muito importante a ser levada em consideração em atividades com uso de jogos é a forma de avaliar. Nesse sentido, Borin (2007) acredita que uma maneira do professor fazer essa avaliação é solicitar aos alunos que registrem suas jogadas, pois com elas será possível analisar descobertas e/ou estratégias vencedoras. A autora também acredita que outra forma seria o professor circular entre os alunos enquanto eles jogam, analisando o desenvolvimento da linguagem lógica, as estratégias de cada grupo, as habilidades de preverem as jogadas dos adversários, capacidade de tomar decisões. Dessa forma, o professor estaria buscando verificar se os objetivos estabelecidos para aquele jogo estão sendo alcançados e, ainda, intervir sempre que julgar necessário a fim de orientar as discussões.

Apoiamo-nos na literatura estudada para o planejamento e desenvolvimento das atividades aplicadas, as quais passamos a descrever e analisar nos próximos dois tópicos deste trabalho. 


\section{DESCRIÇÃO DO CASO}

A atividade contou com uma carga horária de três horas, foi desenvolvida no dia 27 de maio de 2019, com uma turma ${ }^{3}$ do $7^{\circ}$ ano do Ensino Fundamental de uma escola pública da cidade de Formiga/MG e, é resultado de uma proposta de uso de jogos em aulas de Matemática, tendo em vista as discussões que foram realizadas na disciplina Laboratório para o Ensino de Matemática no curso de Licenciatura em Matemática do IFMG Campus Formiga, cursada pelas duas primeiras autoras em 2019/1. A escolha da turma se deve ao fato de essa já ser acompanhada pelas duas primeiras autoras durante atividades do Programa de Residência Pedagógica ${ }^{4}$.

O principal objetivo das atividades desenvolvidas foi trabalhar as quatro operações básicas, como também as expressões numéricas, induzir os alunos a criar estratégias por meio da observação, hipótese e experimentação, desenvolver neles a capacidade de raciocínio lógico e indutivo, despertar a criatividade e o interesse pelas aulas de Matemática, além de investigar se os jogos constituem um recurso didático que contribui para a abordagem de conteúdos matemáticos em sala de aula, no caso, as quatro operações básicas, e oportunizar a vivência em sala de aula com uma atividade lúdica enquanto ainda docentes em formação.

\subsection{O Jogo Contig 60}

O Contig 60 é um jogo de estratégia que se baseia no cálculo mental com as quatro operações básicas (adição, subtração, multiplicação e divisão), no qual cada jogador deve montar expressões numéricas afim de obter o número desejado para marcar mais pontos no tabuleiro, conforme as regras do jogo. Ele também desenvolve o raciocínio lógico dos alunos ao levantarem hipóteses das melhores jogadas e buscarem estratégias para vencer (GRANDO, 2000).

Os materiais necessários para realização do jogo foram: um tabuleiro de números (Figura 1); três dados de seis faces; marcadores de EVA com duas cores distintas; folha contendo as regras do jogo; folha de registro das atividades, em que os alunos realizaram os

\footnotetext{
${ }^{3}$ Participaram da atividade 33 alunos na faixa etária entre 12 a 13 anos de idade.

${ }^{4}$ O Programa de Residência Pedagógica é uma das ações que integram a Política Nacional de Formação de Professores e tem por objetivo induzir o aperfeiçoamento da formação prática nos cursos de licenciatura, promovendo a imersão do licenciando na escola de educação básica, a partir da segunda metade de seu curso.
} 
cálculos necessários durante o jogo; folha com situações problema de jogo e folha com questionário de avaliação da atividade.

Acerca das situações problema, Grando (2000, p. 45) destaca que "A resolução dos problemas de jogo propicia uma análise mais específica sobre o jogo, onde os problemas abordam diferentes aspectos do jogo que podem não ter ocorrido durante as partidas”. Ainda de acordo com a autora, essas situações podem fazer com que os alunos aperfeiçoem suas jogadas, melhorando seus desempenhos em próximas rodadas.

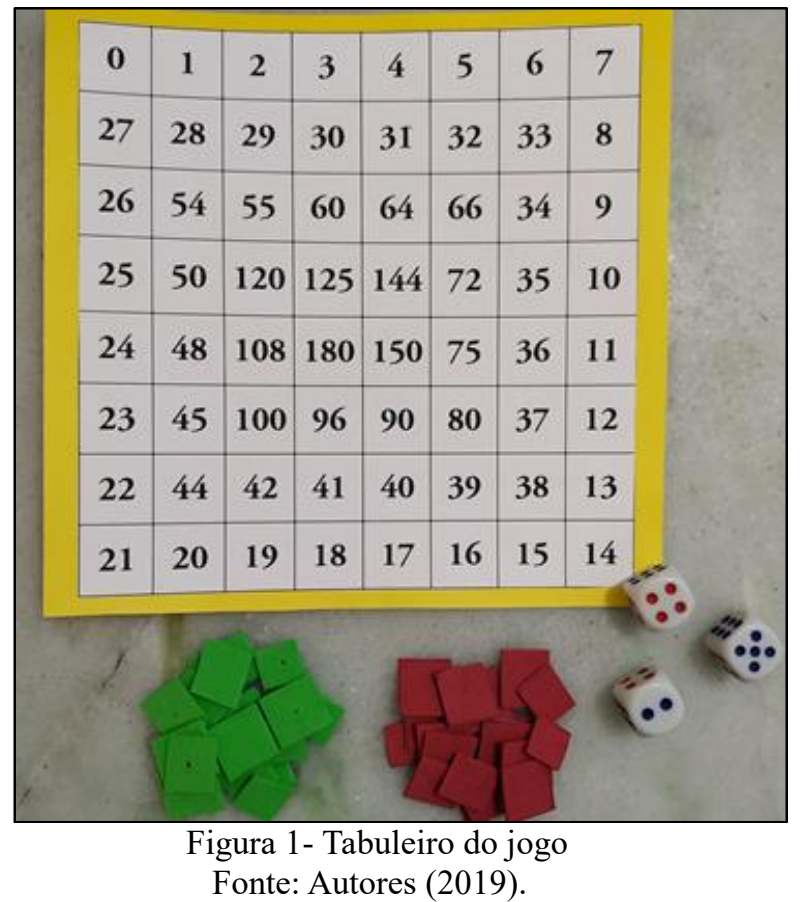

As duplas jogam alternadamente. A primeira dupla inicia lançando os três dados e, com os números obtidos, deve fazer uma expressão matemática utilizando uma ou duas ${ }^{5}$ das quatro operações básicas. Por exemplo, com os números dos dados um, dois e cinco poderá ser construída a sentença $(1 \times 2)+5=7$, sendo assim, o número sete deverá ser marcado no tabuleiro com a ficha da cor correspondente da dupla.

Um ponto é marcado quando o jogador colocar sua ficha em uma casa vazia que seja adjacente, ou seja, que tenha fronteira com uma casa que já possua uma ficha (horizontalmente, verticalmente ou diagonalmente). Se o marcador for colocado em um espaço adjacente a mais de uma ficha, poderá marcar mais pontos, por exemplo, digamos que haja marcadores nas casas cinco, seis e 33 (ver tabuleiro), se na próxima jogada, a dupla marcar a casa 32, ganhará três pontos, pois ela é adjacente a cinco verticalmente, a seis diagonalmente e a 33 horizontalmente.

\footnotetext{
${ }^{5}$ Não é possível utilizar mais que duas operações, visto que serão utilizados três números dos dados para criar as sentenças.
} 
Caso uma dupla não consiga construir uma sentença com os números resultantes nos dados e passar a vez, a dupla adversária, se julgar possível, poderá fazer uma sentença com aqueles números, fazendo assim, duas jogadas consecutivas.

Se uma das duplas perceber que a dupla adversária construiu uma sentença errada, ela poderá acusar o erro, ganhar dois pontos, e a dupla que cometeu o erro deverá retirar seu marcador do tabuleiro, caso já o tenha nele colocado.

Vence a dupla que conseguir fazer $30^{6}$ pontos primeiro, ou aquela que conseguir alinhar cinco de suas marcas na horizontal, vertical ou diagonal (sem marcas do oponente intercaladas).

\subsection{Desenvolvimento da atividade}

Inicialmente levamos os alunos para uma sala afastada das demais - a pedido da professora deles - para que o barulho não atrapalhasse as aulas dos demais professores. Como vimos, o barulho é algo esperado para esse tipo de atividade (BORIN, 2007). Para nós, a realização da atividade em outra sala acabou sendo uma vantagem, pois já deixamos o espaço organizado com as mesas agrupadas e os materiais necessários já sobre as mesmas, o que contribuiu em relação ao tempo, que costuma ser maior nesse tipo de atividade comparado ao tempo gasto em aulas tradicionais (LORENZATO, 2009.

Fizemos a apresentação da proposta aos alunos e, em seguida, a leitura das regras. Logo após, solicitamos aos alunos que começassem a jogar e os lembramos que todas as jogadas deveriam ser anotadas na folha de registros da dupla. Essas folhas de registros desenvolvem um papel importante na hora do jogo, pois, conforme Borin (2007) aponta, podem ser utilizadas para avaliação da atividade.

Os alunos ficaram uma hora jogando e, logo após, iniciaram a resolução das situações problema (GRANDO, 2000, p. 223-224) referentes ao jogo, as quais são apresentadas a seguir, juntamente com as respectivas respostas.

Situação 1: Temos a seguinte situação de jogo: peças colocadas nas casas 29, 31, 54, 125, 66 e 72.

a) Quantas possibilidades o próximo jogador tem de ganhar 3 pontos? E 2 pontos?

Resposta: Três possibilidades. Oito possibilidades.

b) Para cada uma destas situações, indique uma solução possível (números e operações).

Resposta:

${ }^{6}$ Optamos pela marcação de 30 pontos, devido ao tempo de aplicação da atividade, porém no jogo estudado (GRANDO, 2000), a pontuação para que haja um ganhador é de 60 pontos. 
Três pontos: $\underline{55}=(5+6) \times 5$

$\underline{60}=(5+5) \times 6$ ou $5 \times 2 \times 6$

$$
\underline{144}=6 \times 4 \times 6
$$

Dois pontos: $\underline{3}=1+1+1 \quad \underline{34}=5 \times 6+4$ ou $6 \times 6-2$

$$
\begin{array}{ll}
\underline{28}=5 \times 5+3 \text { ou } 6 \times 5-2 & \underline{35}=5 \times 6+5 \\
\underline{30}=5 \times 6 \times 1 & \underline{120}=5 \times 4 \times 6 \\
\underline{32}=5 \times 6+2 & \underline{150}=5 \times 5 \times 6
\end{array}
$$

Situação 2: Um jogador já tirou 5 em um dos dados. Quanto ele precisa tirar nos outros dois dados e quais operações precisa fazer para que possa colocar sua peça na casa 28 ?

Resposta: Existem 3 possibilidades para obter o número 28, que são tirar os números:

6 e 2 com as operações de multiplicação e subtração $(6 \times 5)-2 ; 5$ e 3 com as operações de multiplicação e adição $(5 \times 5)+3 ; 2$ e 4 com as operações de adição e multiplicação $(5+2) \times 4$.

Situação 3: As seguintes casas estão preenchidas: 9, 10, 31, 34, 36, 55, 60, 66, 72 e 108.

a) Para conseguir o maior número de pontos, qual casa deve ser preenchida?

Resposta: A casa de número 35.

b) Que números você precisaria tirar nos dados para preencher esta casa, sendo válidas somente as operações de adição e multiplicação? Apresente 3 soluções distintas possíveis.

Resposta: $5 \times 6+5(5+2) \times 5(4+3) \times 5$

Situação 4: Qual o número máximo que poderia constar no tabuleiro? Justifique a sua resposta.

Resposta: O número $216(6 \times 6 \times 6)$, devido ao fato de o maior contido no dado ser o 6 .

Situação 5: Qual é o maior número do tabuleiro que se pode obter, utilizando:
a) Somente subtrações?
b) Somente divisões?
c) Uma adição e uma multiplicação?
d) Uma adição e uma subtração?

Resposta:
a) $\underline{4}=6-1-1$
b) $\underline{6}=6 \div 1 \div 1$
c) $\underline{72}=(6+6) \times 6$
d) $\underline{11}=6+6-1$

Situação 6: Situação do tabuleiro (peças colocadas):

Vermelhas: $1-2-29-31-34-36-37$-próximo a jogar

Verdes: $3-5-32-54-60-64-80-150$

a) Se os números que saíram nos dados foram 5,5 e 2, qual a melhor jogada a ser feita pelo jogador vermelho? Justifique a sua resposta. 
Resposta: Escolher a casa de número 35 ou a casa de número 12 pois, marcando a casa 28 ele faria três pontos, entretanto com esses números $(5,5$ e 2) não conseguimos obter o número 28 ; já os números 35 e 12 são possíveis, ganhando, assim, dois pontos.

b) Com esses números, 5,5 e 2, é possível chegar no número 0 (zero)? Justifique sua resposta.

Resposta: Sim, através das operações $(5-5) \times 2=0$ ou $(5-5) \div 2=0$.

Situação 7: Por que o número 47 não consta no tabuleiro? Justifique.

Resposta: Por ser primo, não permite estabelecer, dentre as quatro operações básicas, a utilização de três números de 1 a 6 que, operados, resultem em 47.

Durante a realização de toda a atividade, circulamos entre as mesas buscando orientar as duplas e tirar as dúvidas que foram surgindo, fazendo questionamentos que redirecionassem o raciocínio dos alunos, o que é coerente à orientação de Borin (2007) em atividades com jogos.

Ao término da resolução das situações problema, foi entregue uma folha com o questionário de avaliação da atividade a qual objetivou obtermos um feedback dos alunos sobre a atividade desenvolvida com eles.

As folhas de registro, o questionário final e as resoluções das situações problema foram recolhidas e posteriormente analisadas. Após análises, retornamos à sala de aula da turma participante da proposta, em horário regular - cedido pela professora da turma, para apresentarmos aos alunos os resultados e discutirmos a proposta. Esse momento foi extremamente enriquecedor, pois nos permitiu sanar as dúvidas detectadas nos registros feitos pelos alunos e contribuir com um alcance ainda maior dos objetivos propostos.

\section{AVALIAÇÃO DA PROPOSTA}

A avaliação da intervenção baseou-se na análise dos resultados obtidos por meio das observações feitas em sala de aula durante toda a atividade desenvolvida e também nos registros das jogadas, nas respostas dadas às situações problema e nas respostas dos alunos ao questionário final.

\subsection{Análise dos registros apresentados pelos alunos}

Analisando os registros das jogadas feitas, verificamos que foram formadas, ao todo, 135 sentenças matemáticas - variando de sete a 11 por dupla - e que sete duplas erraram somente 
um cálculo dentre as sentenças que formaram, sendo que as demais acertaram todos os cálculos. Diante desses dados, podemos afirmar que o número de erros foi extremamente baixo, aproximadamente 5,2\% das sentenças formadas tiveram erros nos cálculos.

Na Figura 2a, vemos o registro de uma dupla que não se atentou à ordem dos números na operação de divisão - vale destacar que esta operação foi a menos utilizada na construção das sentenças. $\mathrm{O}$ resultado apresentado pela dupla nos leva a crer que a ideia era fazer $(6 \div 2) \times$ $1=3$, e não $(2 \div 6) \times 1$. Na Figura 2 b, é possível ilustrar um equívoco nos cálculos de uma expressão que resultaria em número negativo. Como só ocorreu um erro desse tipo, ou seja, cálculos que resultavam em números negativos e apresentaram erros, acreditamos que ele também seja decorrente de falta de atenção. Já a Figura 2c apresenta um erro devido ao não uso de parênteses - para se chegar ao resultado possivelmente desejado, 55, o correto seria fazer $(5+6) \times 5$, ou devido à resolução dos cálculos na ordem errada, pois, sem os parênteses, o correto seria5 $+\underbrace{6 \times 5}_{30}=5+30=35$.

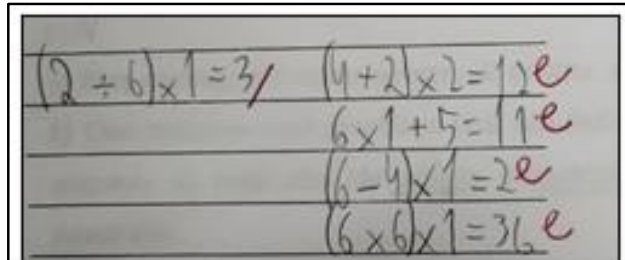

(a)

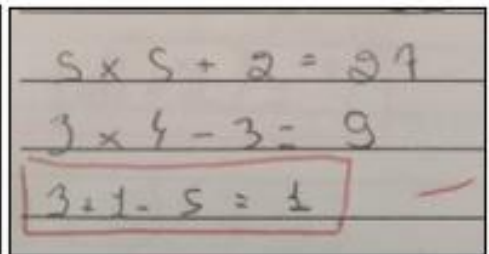

(b)

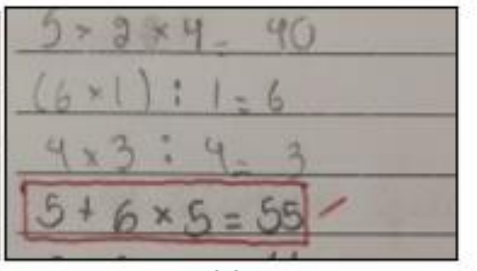

(c)

Figura 2 - Alguns registros dos alunos com erros de cálculos

Fonte: Turma do $7^{\circ}$ Ano do Ensino Fundamental.

Os outros quatro registros errôneos, decorrentes de erros nas tabuadas das quatro operações básicas, são apresentados na Figura 3.

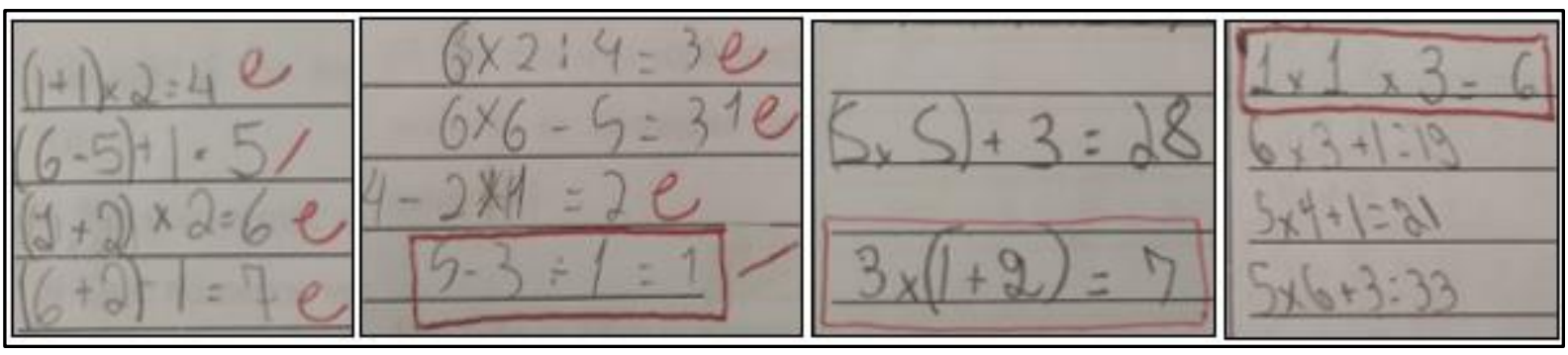

Figura 3 - Registros dos alunos com erros de cálculos

Fonte: Turma do $7^{\circ}$ Ano do Ensino Fundamental.

Referente à marcação de pontos, fizemos uma média dos pontos marcados pelas duplas no jogo, que foi sete (aproximadamente 23\% do previsto inicialmente para ser vencedor). Essa média de pontos trouxe uma reflexão importante sobre a aplicação desse jogo. 
Não houve dupla vencedora que tenha marcado 30 pontos e, então, ao final do tempo estipulado, foram declaradas vencedoras aquelas que mais haviam pontuado. $\mathrm{O}$ jogo também teve três duplas ganhadoras devido à regra de posicionar cinco marcadores na horizontal, vertical ou diagonal sem peças do oponente intercaladas.

Para melhor visualização e análise dos dados obtidos nas situações problema propostas, organizamos a Tabela 1 com os resultados da correção.

Tabela 1- Quantidade de acertos/erros nas situações problema

\begin{tabular}{|c|c|c|c|c|}
\hline Questões & Acertos & Erros & Acertos Parciais & Em branco \\
\hline \multirow{2}{*}{$\begin{array}{l}\text { 1. a) } \\
\text { b) }\end{array}$} & 12 & 4 & 0 & 0 \\
\hline & 8 & 0 & 8 & 0 \\
\hline 2. & 15 & 0 & 0 & 1 \\
\hline \multirow{2}{*}{$\begin{array}{r}\text { 3. a) } \\
\text { b) }\end{array}$} & 15 & 0 & 0 & 1 \\
\hline & 11 & 0 & 3 & 2 \\
\hline 4. & 8 & 8 & 0 & 0 \\
\hline 5. a) & 10 & 6 & 0 & 0 \\
\hline b) & 10 & 5 & 0 & 1 \\
\hline c) & 8 & 7 & 1 & 0 \\
\hline d) & 11 & 4 & 0 & 1 \\
\hline \multirow{2}{*}{$\begin{array}{l}\text { 6. } \\
\text { a) } \\
\text { b) }\end{array}$} & 8 & 2 & 2 & 4 \\
\hline & 6 & 6 & 1 & 3 \\
\hline 7. & 7 & 6 & 0 & 3 \\
\hline
\end{tabular}

Fonte: Autores (2019).

Com base nos registros e nas observações das discussões, podemos apontar que alguns alunos apresentaram dificuldade na interpretação das questões. Bittencourt (2008, p.4) destaca que "[...] ler e interpretar são fundamentais porque esses fatores é que vão ordenar logicamente o pensamento".

Destacamos a situação problema quatro, em que metade das duplas apresentou 180 como resposta para o maior número que poderia constar no tabuleiro, e justificaram que "180 é o maior número do tabuleiro", ou seja, os alunos interpretaram que a perguntava objetivava saber qual era o maior número que constava no tabuleiro, e não, que poderia constar. A Figura 4 ilustra a interpretação apresentada. 


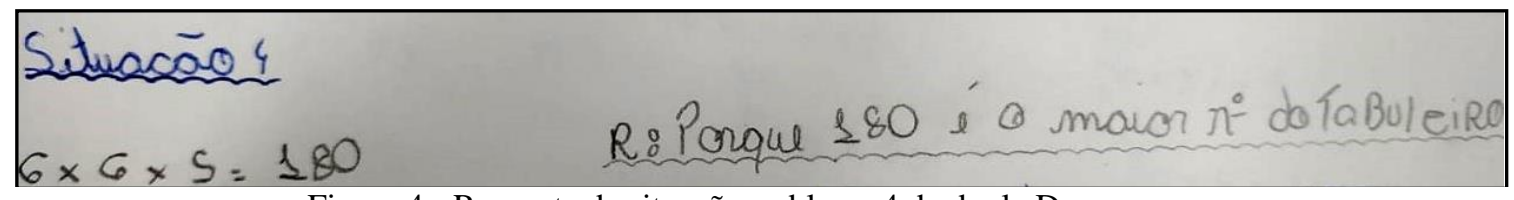

Figura 4 - Resposta da situaçãoproblema 4 da dupla D Fonte: Turma do $7^{\circ}$ Ano do Ensino Fundamental.

Também destacamos a interpretação na situação problema cinco. Os registros das duplas que erraram mostram que, para responder qual o maior número do tabuleiro que se poderia obter utilizando as operações indicadas, os alunos entenderam que era preciso utilizar os maiores números do dado nas sentenças e, dessa forma, acabaram não chegando às respostas corretas.

A situação $6 \mathrm{~b}$ apresentou significativo número de erros/brancos. Três duplas deixaram em branco e, das seis duplas que erraram, cinco responderam "não", sendo que, destas, quatro não justificaram e uma justificou que o número dois iria sobrar - acreditamos que esta dupla tenha pensado em fazer $5-5=0$ e acabou não se atentando para o fato de que seria necessário montar uma sentença com os três números citados no exercício $(5,5$ e 2). Uma dupla respondeu sim, porém apresentou uma justificativa inadequada, conforme podemos ver na Figura 5.

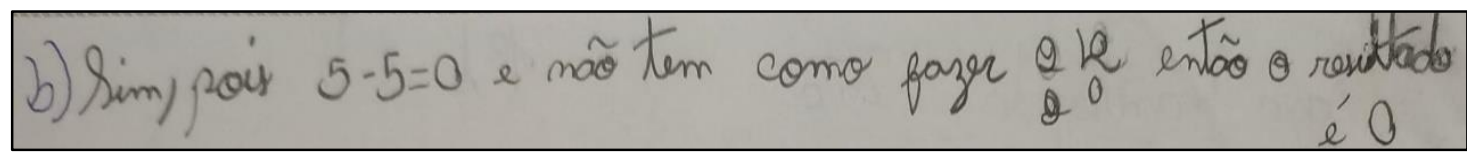

Figura 5 - Resposta da situação problema $6 \mathrm{~b}$ da dupla A Fonte: Turma do $7^{\circ}$ Ano do Ensino Fundamental.

As situações problema exigiam, em sua maioria, análise do tabuleiro, domínio das regras, raciocínio e discussões para se chegar na resposta correta que, em grande parte, deveria ser justificada. Notamos que alguns alunos apresentaram dificuldades em expressar suas justificativas, muitas das vezes não as apresentando ou as apresentando de forma incorreta. Como exemplo, destacamos a situação sete, a qual apresentou diferentes tipos de respostas e, em algumas, não conseguimos compreender o raciocínio utilizado pelo aluno, como é o caso da resposta apresentada na Figura 6.

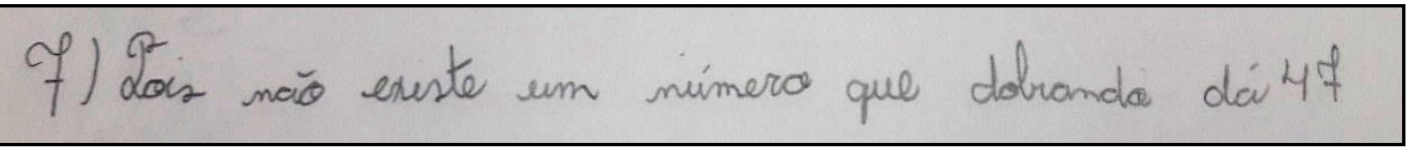

Figura 6 - Resposta da situaçãoproblema 7 da dupla E Fonte: Turma do $7^{\circ}$ Ano do Ensino Fundamental. 
A Figura 7 é um exemplo de resposta, também da situação 7, que ilustra a dificuldade de expressar o raciocínio.

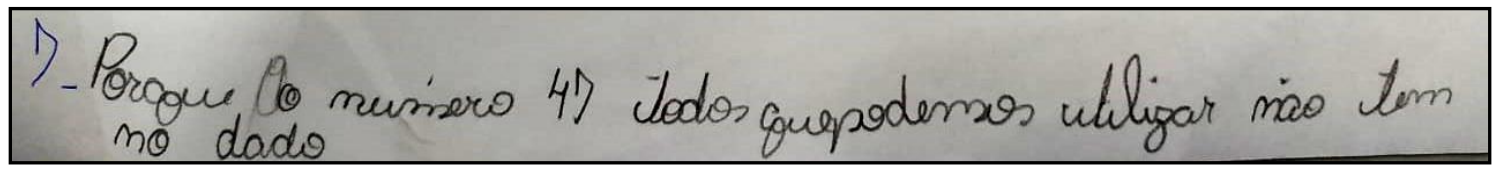

Figura 7 - Resposta da situaçãoproblema 7 da dupla F

Fonte: Turma do $7^{\circ}$ Ano do Ensino Fundamental.

Acerca da dificuldade em apresentarem as justificativas, concordamos com Braz e Castro (2018, p. 19) quando esses apontam que essa dificuldade pode ser "[...] indício de uma falta de hábito dos alunos em escreverem [...] suas ideias [...]”. Os autores ainda apontam que essa dificuldade “[...] nos faz refletir sobre as aulas de Matemática, onde os discentes, normalmente, resolvem exercícios sem a necessidade de representar e/ou explicar, através de palavras, seus raciocínios $[\ldots] ”$.

Detectamos, nos registros das situações problema, alguns erros ao formular as sentenças, os quais podem ter sido ocasionados por desatenção às regras ou ainda, uma tentativa de infringi-las. Nesse sentido, Borin $(2007$, p. 76) ressalta que “[...] os alunos se envolvem de tal forma com a preocupação em ganhar que, muitas vezes, tentam infringir as regras se o adversário é desatento ou ingênuo [...]”".

Abaixo, apresentamos um registro em que a dupla utilizou o número oito, sendo que só poderiam ser usados os números de um a seis, que são os possíveis valores do dado.

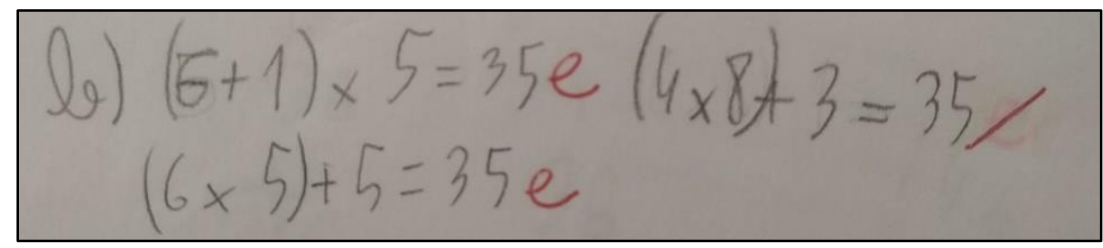

Figura 8 - Resposta da situação problema 3, letra b da dupla A Fonte: Turma do $7^{\circ}$ Ano do Ensino Fundamental.

Tanto durante o jogo como durante a resolução das situações problema, circulávamos entre os alunos e os observávamos, conforme sugere Borin (2007). Percebemos que algumas duplas ajudavam seus adversários a formularem as sentenças. Notamos que a intenção deles não era induzir o adversário ao erro. Isso demonstra que o espírito de competição ficou em segundo plano, e o objetivo tornou-se a cooperação e a socialização. Nesse sentido, acreditamos que a proposta tenha atingido os objetivos além dos previstos e, ainda, destacamos a socialização que se fez presente durante toda a atividade, a qual Grando (2000) destaca que “[...] nesse processo de socialização no jogo, a criança ouve o colega e discute, identificando 
diferentes perspectivas e se justificando. Ao se justificar, argumenta e reflete sobre os seus próprios procedimentos em um processo de abstração reflexiva".

A participação dos alunos, em geral, foi bastante satisfatória, mostraram-se interessados e motivados a jogar e resolver os problemas propostos. O comportamento dos alunos pode ser justificado por Grando (2000), que aponta que a atividade lúdica envolve o desejo e o interesse e que o ato de competir os torna motivados a superar seus limites. Apenas uma dupla não demonstrou interesse pela atividade proposta, apesar do nosso estímulo e esforço para que participasse. Essa dupla não se mostrou disposta a jogar, e nas situaçõesproblema, respondeu apenas à questão 1. Esse tipo de comportamento também é natural e esperado em alguns alunos, tendo em vista que alguns podem não gostar de atividades com jogos (BORIN, 2007).

\subsection{Avaliação, feita pelos autores, da proposta realizada}

Com o jogo Contig 60, foi possível observar que os alunos levantavam hipóteses ao jogar os dados, pois tinham que fazer as sentenças e analisar as melhores jogadas para eles e/ou qual jogada poderia não ser vantajosa para seu adversário. Com isso, faziam discussões e construíam suas estratégias sempre de forma cooperativa com seu parceiro de jogo. Essa cooperação é importante para o pensamento da criança (PIAGET, 1998 apud GRANDO, 2000, p. 31), pois:

[...]na medida em que ela é capaz de renunciar aos seus desejos e interesses próprios para pensar em função de uma realidade comum, de um interesse coletivo e pode se colocar no ponto de vista dos outros, é possível que "a inteligência adote a atitude, própria ao espírito científico desde suas formas mais simples, que consiste em dissociar o real das ilusões antropocêntricas.

Algumas duplas, ao colocarem seus marcadores nas casas do tabuleiro, analisavam as futuras casas nas quais pontuariam e já falavam quais números gostariam que saíssem nos dados, demonstrando uma análise de possibilidades no jogo, o que implica que algumas duplas conseguiram jogar operatoriamente. Isso significa "ser capaz de analisar as possibilidades de jogadas, elaborar estratégias, testá-las e avalia-las" (GRANDO, 2000, p. 40). Além disso, ao detectarem que fizeram uma jogada errada, ou seja, que não marcaram pontos sendo que, com os números obtidos nos dados era possível marcar, eles reelaboravam suas estratégias, aprendendo com os erros cometidos. Nessa fase do jogo, detecta-se a presença do raciocínio dedutivo " $[\ldots]$ que se baseia na análise tanto das jogadas certas como das erradas, o que faz o jogador elaborar e reelaborar hipóteses a todo momento" (BORIN, 2007, p. 16). 
Julgamos pertinente destacar a importância da observação e da circulação entre as mesas enquanto os alunos estão envolvidos na atividade, pois eles percebem que estão de certa forma, sendo avaliados e, diante das dúvidas que surgiam, discutiam com o colega de dupla e, por vezes, nos chamavam. Essa orientação do professor durante a atividade é fundamental para que os objetivos sejam alcançados e para que o conhecimento seja construído. Observando os registros do jogo de algumas duplas, notamos um avanço quando comparamos os registros iniciais com os finais, o que pode ser decorrente das discussões ocorridas.

Já o questionário final, aplicado aos alunos participantes das atividades, nos permitiu saber a opinião dos mesmos acerca da proposta. As perguntas feitas foram:

1) Você gostou da atividade aplicada? Justifique.

2) Qual a sua opinião sobre a utilização de Jogos para ensinar Matemática?

3) Você acha que facilita o aprendizado, a utilização de jogos?

4) Você encontrou dificuldades durante a atividade? Quais?

Na pergunta 1, todos os alunos afirmaram que gostaram da atividade, inclusive os alunos da dupla que se mostrou desinteressada. De maneira geral, afirmaram que a proposta foi uma forma divertida de aprender, diferente, interessante e que os fez racionar, auxiliando-os no aprendizado. A seguir, destacamos duas respostas.

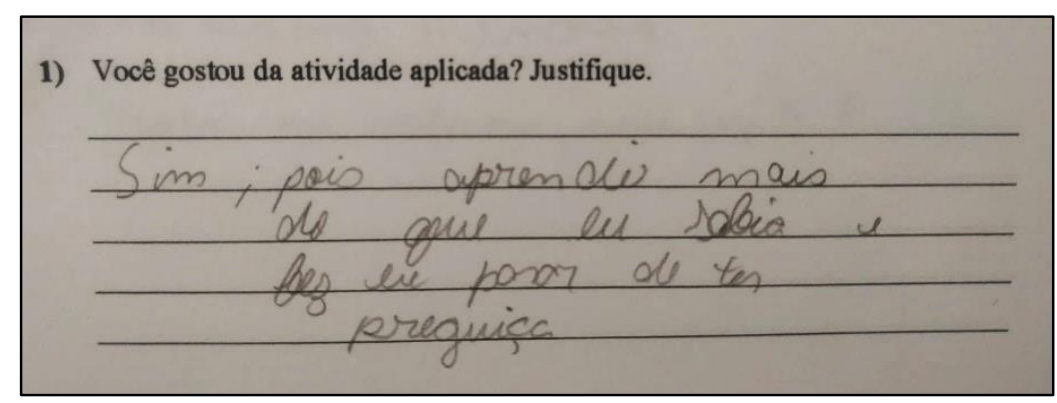

Figura 9 - Resposta aluno 1 à pergunta 1

Fonte: Turma do $7^{\circ}$ Ano do Ensino Fundamental.

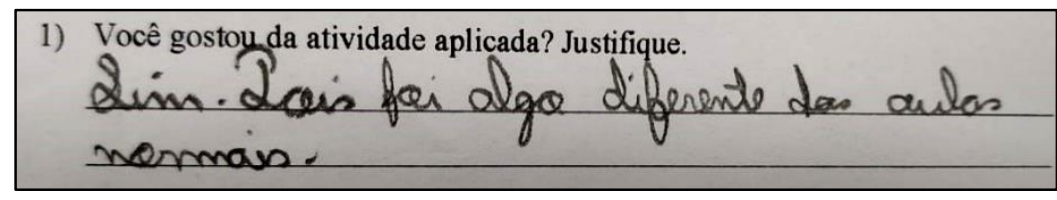

Figura 10 - Resposta aluno 2 à pergunta 1

Fonte: Turma do $7^{\circ}$ Ano do Ensino Fundamental.

As respostas dadas pelos alunos vão ao encontro do que destaca Grando (2000, p. 26), quando a autora diz que "Quando são propostas atividades com jogos para os alunos, a reação 
mais comum é de alegria e prazer pela atividade desenvolvida [...]", justificando o fato de todos terem gostado da atividade.

$\mathrm{Na}$ pergunta 2, os alunos relataram que esse tipo de atividade incentiva, estimula e facilita o aprendizado, uma vez que, por gostarem, acabam se dedicando mais, além de terem achado uma forma divertida de estudo. Um dos alunos disse que deveriam incentivar mais esse tipo de atividade nas aulas, conforme podemos ver no registro abaixo:

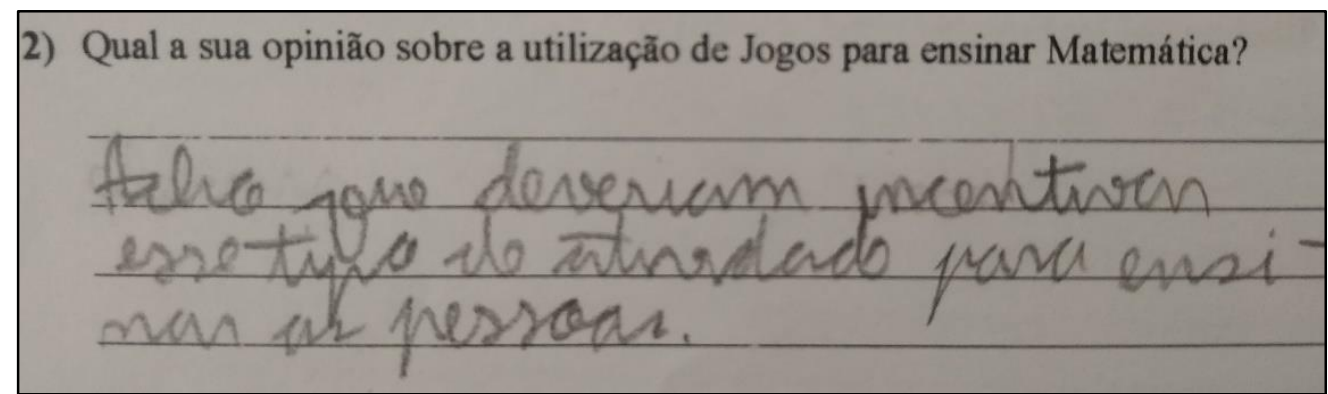

Figura 11 - Resposta do aluno 4 à pergunta 2

Fonte: Turma do $7^{\circ}$ Ano do Ensino Fundamental.

$\mathrm{Na}$ terceira pergunta, todos responderam que acham que o jogo pode facilitar o aprendizado. Alguns justificaram dizendo que é uma forma menos entediante de estudar, que o jogo relaciona raciocínio com diversão, e que o fato de querer vencer serve como incentivo. Nesse sentido, entendemos que o jogo representou, conforme sugere Grando (2000), uma atividade desafiadora e desencadeadora do processo de aprendizagem. Abaixo, apresentamos duas respostas.

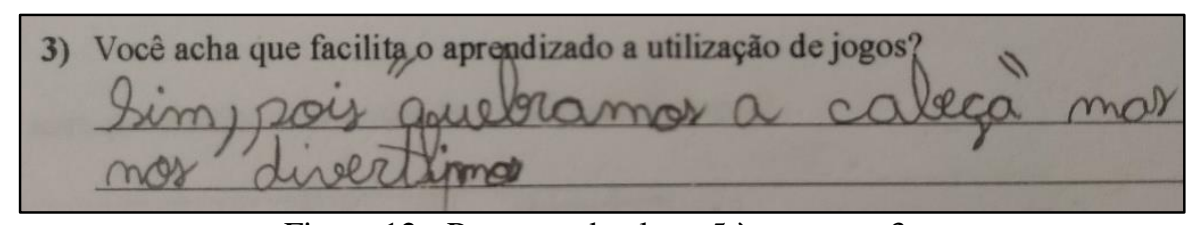

Figura 12 - Resposta do aluno 5 à pergunta 3

Fonte: Turma do $7^{\circ}$ Ano do Ensino Fundamental.

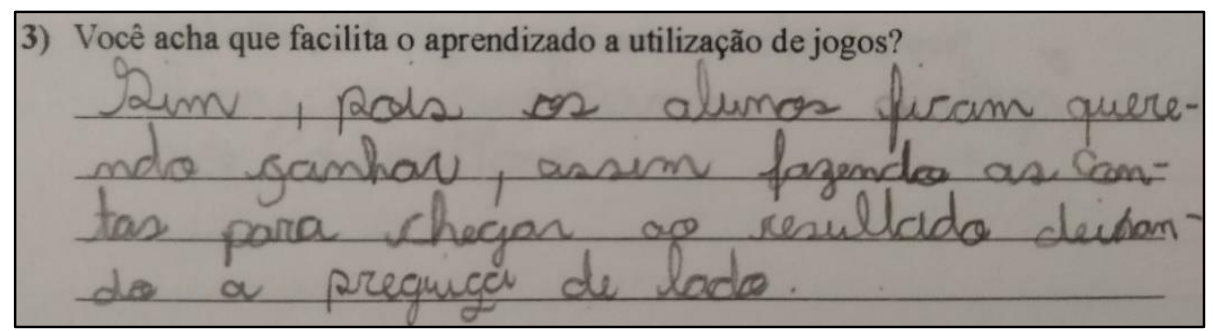

Figura 13 - Resposta do aluno 6 à pergunta 3

Fonte: Turma do $7^{\circ}$ Ano do Ensino Fundamental. 
Por fim, na quarta e última pergunta, buscamos saber as dificuldades encontradas pelos alunos durante o desenvolvimento da atividade. Dos 33 alunos participantes, 25 disseram que encontraram dificuldades e oito afirmaram que não. Ao analisarmos as respostas, percebemos a conexão delas com os erros apresentados nas folhas de registro, por exemplo, uma dupla relatou "Sim, a folha de atividades, na questão 1 não entendi direito". Essa dupla não conseguiu identificar as possibilidades de marcar dois e três pontos como pedia a questão 1, considerou apenas duas possibilidades para cada situação, sendo que para dois pontos eram três e, para três pontos, oito possibilidades.

Ainda na pergunta 4, um aluno escreveu: "Sim, mas ao longo do tempo fui superando a maioria delas, algumas sozinho e algumas com minha dupla”. O relato desse aluno demonstra uma interação construtiva de aprendizagem, sendo assim, vemos que os jogos podem propiciar um ambiente de construção de conhecimento, como afirma Lara (2003).

Quatro alunos também relataram dificuldades de interpretação das questões, e outros quatro, apontaram dificuldade nas "contas”. Abaixo, destacamos um registro.

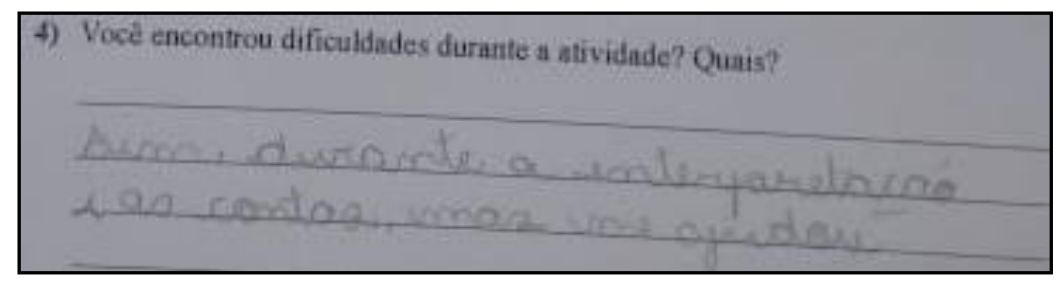

Figura 14 - Resposta do aluno 7 à pergunta 4 Fonte: Turma do $7^{\circ}$ Ano do Ensino Fundamental.

Por fim, destacamos que o momento em que voltamos na sala de aula para apresentar aos alunos os resultados obtidos e discutir as situações problema propostas foi fundamental para um alcance ainda maior dos objetivos propostos. Enfatizamos e discutimos cada situação e os alunos puderam sanar as dúvidas que ainda haviam ficado após a aplicação da atividade.

\section{CONCLUSÃO}

Consideramos que o desenvolvimento das atividades com o Jogo Contig 60 gerou resultados satisfatórios. Os objetivos propostos - trabalhar as quatro operações básicas, a formulação e resolução de expressões numéricas e o desenvolvimento dos raciocínios lógico e indutivo - foram alcançados.

Acreditamos que o uso de jogos na sala de aula é uma das diversas formas que o professor tem de buscar outras estratégias no intuito de contribuir com o processo de ensino e 
aprendizagem da Matemática. Nesse sentido, destacamos o interesse, a satisfação e a motivação que o jogo despertou nos alunos, além do espírito de cooperação e socialização.

A experiência com a proposta nos faz acreditar que, em atividades como a que vivenciamos, o professor tem um contato mais próximo com o aluno e, dessa forma, pode perceber dúvidas e defasagens que, muitas vezes, passam despercebidas em uma aula tradicional. Não é objetivo deste trabalho julgar ou criticar o modelo tradicional de ensino, mas trazer uma proposta diferenciada que auxilie tanto o professor quanto o aluno, levando em consideração os resultados obtidos através da experiência aqui compartilhada, e das demais que a literatura aborda.

Por fim, julgamos que a atividade proposta, além de contribuir para o estudo das quatro operações básicas, também trouxe reflexões importantes para nós, futuros docentes e, ainda, oportunizou a mobilização dos saberes advindos da formação profissional para o magistério, saberes esses obtidos durante a formação e socialização nas instituições de ensino formadoras de professores (TARDIF, 2008). Esses se revelaram através do planejamento da atividade, da organização do tempo e da turma, do uso de recursos didáticos, entre outros aspectos do campo da didática estudados durante o curso de formação inicial das licenciandas.

Destacamos, também, a mobilização dos saberes experienciais, adquiridos, segundo Tardif (2008), através da prática do ofício na sala de aula e da troca de experiência entre os pares. Tivemos a oportunidade de vivenciar uma de nossas primeiras práticas em sala de aula e poder contar com a experiência da professora orientadora e da professora da turma em que desenvolvemos a proposta. Por fim, acrescentamos que muitas das discussões geradas a partir dos textos estudados na disciplina Laboratório para o Ensino de Matemática puderam ser vistas na prática com a experiência, o que consideramos extremamente enriquecedor.

\section{REFERÊNCIAS}

BITTENCOURT, J. F. A importância da leitura e interpretação do texto do problema matemático. Artigo Universidade Estadual de Ponta Grossa: 2008. Disponível em: http://www.diaadiaeducacao.pr.gov.br/portals/pde/arquivos/1797-8.pdf. Acesso em: 20 maio de 2019.

BORIN, J. Jogos e resolução de problemas: uma estratégia para as aulas de matemática. 6. ed. São Paulo: IME-USP, 2007. 100 p. 
BRAZ, L. H. C.; CASTRO, G. T. de. O uso do software GeoGebra no ensino das funções afim e quadrática: uma experiência com alunos do $2^{\circ}$ ano do ensino médio. ForScience: revista científica do IFMG, Formiga, v. 6, n. 1, e00338, jan./jul. 2018.

GRANDO, R. C. O conhecimento matemático e o uso de jogos na sala de aula. 2000. 224 f. Tese (Doutorado em Educação) - Universidade Estadual de Campinas, Campinas, 2000. Disponível em:

http://www.educadores.diaadia.pr.gov.br/arquivos/File/2010/artigos_teses/2010/Matematica/t ese_grando.pdf . Acesso em: 15 mai. 2019.

LARA, I. C. M. de. Jogando com a matemática na educação infantil e séries iniciais. São Paulo: Rêspel, 2003.

LORENZATO, S. O laboratório de ensino de matemática na formação de professores. 2. ed. Campinas: Autores Associados, 2009. (Coleção Formação de Professores).

NACARATO, Adair Mendes. Eu trabalho primeiro no concreto. Revista de Educação Matemática, São Paulo, v. 9, n. 9-10, p. 1-6, 2005.

SANTOS, J. L. dos.; RODRIGUES, M. A. T. Jogos matemáticos como ferramenta de aprendizagem no $5^{\circ}$ ano do Ensino Fundamental. Revista Thema, Pelotas, v. 15, n. 2, p. 371$388,2018$.

STRAPASON, L. P. R.; BISOGNIN, E. Jogos pedagógicos para o ensino de funções no primeiro ano do ensino médio. Bolema, Rio Claro, v. 27, n. 46, p. 579-595, ago. 2013. TARDIF, M. Saberes docentes e formação profissional. 9. ed. Petrópolis: Vozes, 2008.

\section{DADOS DOS AUTORES}

Nome: Lúcia Helena Costa Braz

E-mail: lucia.helena@ifmg.edu.br

Curriculum Lattes: http://lattes.cnpq.br/8127215627397170

Mestrado Profissionalizante em Matemática pela Universidade Federal de Lavras; graduação em Licenciatura Plena em Matemática pela Faculdade de Filosofia, Ciências e Letras de Boa Esperança e Licenciatura Plena em Física pelo Centro Universitário de Formiga. Foi professora da Educação Básica em escolas das redes pública e particular de Formiga e do Ensino Básico, Técnico e Tecnológico do IFSul de Minas/Campus Poços de Caldas. Atualmente é professora efetiva do Instituto Federal de Minas Gerais - Campus Formiga atuando no curso de Licenciatura em Matemática. É pesquisadora do grupo de pesquisa Núcleo Institucional de Novas Tecnologias Aplicadas ao Ensino (NINTAE), do Instituto Federal de Minas Gerais. Tem interesse nas áreas: História de formação de professores, Investigações Matemáticas, Metodologias de Ensino de Matemática, Formação de professores, Tecnologias aplicadas ao ensino de Matemática, Estatística.

Nome: Lucimar Alves de Almeida

E-mail: 1ucimaralves0212@gmail.com

Curriculum Lattes: http://lattes.cnpq.br/1065893479046211 
Graduação em Licenciatura em Matemática pelo Instituto Federal de Educação, Ciência e Tecnologia de Minas Gerais - Campus Formiga. Possui formação no Curso Técnico em Segurança do Trabalho pelo Cecon - Formiga.

Nome: Caroline Ester Felicíssimo Pinto

E-mail: carolinepinto1709@gmail.com

Curriculum Lattes: http://lattes.cnpq.br/9245059128880777

Graduanda em Licenciatura em Matemática pelo Instituto Federal de Educação, Ciência e Tecnologia de Minas Gerais - Campus Formiga. 